\title{
Okul Öncesi Öğretmen-Çocuk Etkileşimlerinin Niteliğine Etki Eden Faktörler
}

\author{
Factors Affecting The Quality Of Preschool Teacher-Child Interactions
}

\author{
Savaş EVCIN* iD, Rengin ZEMBAT iD
}

\begin{abstract}
ÖZ
Bu makalenin amacı okul öncesi öğretmen-çocuk etkileşimlerinin kalitesi ile ilişkili faktörler üzerine yapılmış çalışmaları derleyerek alana Türkçe bir kaynak kazandırmaktır. Okul öncesi dönem gelişimsel ilerleme hızının en yüksek olduğu periyot olarak kabul edilir. Bu dönemde çocuğun yakın çevresinde bulunan yetişkinlerin gelişim üzerinde önemli etkileri vardır. Çoğu zaman bu yetişkin figürü ebeveynlerdir. Ancak her iki ebeveynin de çalıştığı aile sayısındaki artışa paralel olarak, küçük çocuklar zamanlarının önemli bir kısmını okul öncesi kurumlarda ve ebeveyn olmayan yetişkinler (okul öncesi öğretmenler) ile etkileşimde bulunarak geçirmektedirler. Araştırmalar okul öncesi öğretmen-çocuk etkileşimlerinin, çocukların gelişimi üzerinde önemli etkilerinin olduğunu göstermektedir. Bu nedenle öğretmen-çocuk etkileşiminin kalitesi ile ilişkili faktörleri belirlemek amacıyla çok sayıda çalışma yapılmış ancak birbirleri ile uyumlu olmayan, farklı sonuçlara ulaşılmıştır. Bu durum, öğretmen-çocuk etkileşiminin kalitesine etki eden faktörleri belirlemeyi sağlayacak yeni çalışmalara ihtiyaç duyulduğunu göstermektedir.

Anahtar Kelimeler: Öğretmen-Çocuk Etkileşimi, Okul Öncesi Öğretmen, Okul öncesi, Gelişim.

\section{ABSTRACT}

The aim of this article is to compile studies on preschool teacher-child interactions and to provide a Turkish resource for the field. Preschool period is considered to be a period with the highest rate of developmental progress. In this period, the adults in the child's close environment have significant impacts on development. Most of the time, this adult figure is the parents. However, parallel to the increase in the number of families with two employed parents, young children spend a considerable portion of their time in preschool institutions and interacting with non-parent adults (preschool teachers). Research shows that preschool teacherchild interactions have significant impacts on children's development. For this reason, many studies have been conducted to determine the factors associated with the quality of teacher-child interaction, yielding different results that are not consistent with each other. This shows the need for further studies to determine the factors affecting the quality of teacher-child interaction.
\end{abstract}

Keywords: Teacher-Child Interaction, Preschool Teacher, Preschool, Relationship.

\section{GíRiș}

Okul öncesi dönemdeki çocuk-yetişkin etkileşimleri, çocuğun gelişiminin merkezi bir unsurudur (Pianta, 1997; Sabol ve Pianta, 2012). Çocukların yetişkinlerle ilişkilerini inceleyen çalışmalar da çocuk-yetişkin etkileşimleri ile küçük çocukların davranışları ve gelişimleri arasında güçlü bağlar olduğunu göstermektedir (Ansari, Pianta, Whittaker, Vitiello ve Ruzek, 2020; Castle vd.,, 2016; Commodari, 2013; Hu B., Wang, Song, ve LoCasale-Crouch, 2020; Thomason ve La Paro, 2009). Aile ve okul çevresi bu etkileşimlerin ve gelişimin gerçekleştiği temel ortamlardır (Ivanova, Berechikidze, Gazizova, Gorozhanina ve İsmailova, 2020). Çocukların eğitim aldığı, diğer çocuklar ve yetişkinler ile etkileşimde bulunma ve kendi davranışlarını düzenleme becerilerini kazandiğı okul öncesi ortamlar (Ivanova vd.., 2020), aile çevresinden sonra, erken çocuklukta öğrenme ve gelişim için en önemli bağlam olarak kabul edilmektedir (Suchodoletz, Fäschea, Gunzenhauser ve Hamre, 2014; Zano, 2018).

Her iki ebeveynin çalıştığı aile modelinin hem batıda hem de Asya topluluklarında giderek yaygın hale gelmesi ile küçük çocukların ev dışı ortamlarda bakım oranı da artmıştır (Liu, Zhang, Zhao ve Chan, 2020; Zano, 2018). Artık pek çok küçük çocuk, günlük zamanının önemli bir bölümünü ebeveyn olmayan kişiler ile geçirmektedir (Paulus, Ohmann ve Popow, 2016; de Schipper,

${ }^{*}$ Maltepe Üniversitesi Gelişim Psikolojisi Doktora Programı

Sorumlu Yazar/Correspondence Author: Savaş EVCIN

E-posta/E-mail: evcinsavas@hotmail.com

Geliş Tarihi/Received: 01.11.2021

Kabul Tarihi/Accepted: 25.11.2021

Ç. Yayınlanma Tarihi/Online Published: 30.11.2021 
Riksen-Walraven ve Geurts 2006). Öyle ki günde yaklaşık 14 saat uyanık olduğu bildirilen okul öncesi çocukların (Keefe-Cooperman ve Brady-Amoon 2014), bu sürenin ortalama yarısını (7 saatini) okul öncesi eğitim kurumlarında, geçirdikleri bildirilmektedir (Koles, O’Connor ve Collins 2013). Buna bağlı olarak okul öncesi dönemdeki çocukların, ebeveyn olmayan bir yetişkin ile deneyimledikleri etkileşim miktarı da giderek artmaktadır (de Schipper vd., 2006; Thomason ve La Paro, 2009). Çocuklar, bu etkileşimler aracılı̆̆ ile gelişimleri üzerinde etkide bulunan, kasitlı veya kasıtsız, iyi ve/veya kötü pek çok tutuma maruz kalmaktadırlar (Pianta ve Hamre, 2009) ve bu etkileşimler, çocuğun temel özellikleri üzerinde güçlü ve kalıcı şekilde etkide bulunmaktadır (Thomason ve La Paro, 2009).

Okul öncesi öğretmenler, okul öncesi sınıf sisteminin çocuk üzerinde etkisi en yüksek olan unsuru olarak kabul edilmektedir (Lippard, La Paro, Rouse, ve Crosby, 2018; Suchodoletz vd., 2014; Yang ve Hu, 2019). Öğretmen öğrenci etkileşimlerini ele alan teoriler ve bu teorileri test eden çeşitli araştırmalar da (Baker, Grant ve Morlock 2008; Driscoll ve Pianta, 2010; Hutchings, Martin-Forbes, Daley, ve Williams, 2013; Sutherland vd., 2018;) okul öncesi öğretmenlerinin, çocukların gelişimi üzerinde önemli düzeyde etkide bulunduklarını göstermektedir. Özellikle Bağlanma kuramı, ekolojik sistemler teorisi ve sosyo-kültürel gelişim kuramı öğretmenlerin, çocukların psikolojik yapılanmasına, kritik düzeyde etkide bulunduğunu savunmaktadır (Bergin ve Bergin, 2009; Fani ve Ghaemi, 2011; Qutaiba, 2010; Sabol ve Pianta, 2012; Schuengel, 2012; Verschueren ve Koomen, 2012).

\section{BAĞLANMA KURAMI}

Öğretmen-çocuk ilişkisini ele alan çalışmalar çoğunlukla eğitim ve psikoloji disiplinleri çerçevesinde yürütülmüş ve bu çalışmalar büyük oranda bağlanma kuramını temel almışlardır (Sabol ve Pianta, 2012). Bağlanma, çocuk ile bakıcıları (ebeveynleri veya çocuğa bakan/ilgilenen diğer kişiler) arasındaki duygusal bağ olarak tanımlanmaktadır (Dozier, Stovall, Albus, ve Bates, 2001). Bolwby, çocukların, kendilerine bakım veren kişilerle erken dönemde kurdukları bağlanma ilişkilerinin, çocuğun kendisi ve başkaları hakkındaki inançlarını şekillendirerek, gelecekteki kişiler arası ilişkilerinin niteliğine önemli ölçüde etki ettiğini belirtmektedir (Lynch ve Cicchetti, 1997). Buna göre hayatın ilk yıllarında şekillenen ve kişinin diğer insanlarla etkileşim biçimine yön veren bağlanma biçimi, nispeten kararlılık göstererek ileri yaşlardaki kişiler arası ilişkilerin niteliğini de tayin edebilmektedir (Kesebir, ÖzdoğanKavzoğlu, ve Üstündağ, 2011).

Bütün çocuklar, bir yetişkin ile bağlanma ilişkisi kurar. Ancak bağlanma tarzı, yetişkin-çocuk ilişkisinin niteliğine göre farklılaşabilmektedir (Commodari, 2013). Ainsworth ve Bell, bir dizi araştırmadan sonra küçük çocukların yetişkinlere üç farklı tarzda bağlandıklarını öne sürmüşlerdir; Güvenli, Kaygıılı-Kaçınmacı, Kaygılı-Kararsız. Yakın zamanlarda bu kategorilere "Düzensiz-Dağınık" bağlanma stili de eklenmiştir (Ahmad ve Sahak, 2009). Güvenli bağlanma sağlıklı bir ruhsal gelişme ile ilişkilendirilirken güvensiz bağlanma stilleri çeşitli ruhsal problemler ile ilişkilendirilmektedir (Tüzün ve Sayar, 2006). Bağlanma stili, çocuğun bakım veren kişi ile ilişkisinin kalitesini yansıttığı ve ayrıca çocuğun daha sonraki kişilerarası işlevleriyle ilişkili olduğu için araştırmacılar tarafından özellikle önemli kabul edilir (Dozier vd., 2001).

Uzun yıllar boyunca bağlanma konusunu ele alan araştırmacılar çoğunlukla ev ortamındaki ebeveyn çocuk ilişkisini inceleyen çalışmalar yürütmüşlerdir. Ancak dikkatler son yirmi yılda okuldaki yetişkin-çocuk ilişkilerine yönelmiş durumdadır (Verschueren ve Koomen, 2012). Bazı araştırmacılara göre küçük yaştaki çocuklar öğretmenleri ile bağlanma veya bağlanmaya benzer ilişkiler kurarlar (Koles vd., 2013). Çocuk eğer öğretmeni ile güvenli bir bağlanma ilişkisi kurarsa sınıf ortamında kendini güvende hisseder ve bu güvende olma duygusu ile içinde bulunduğu çevreyi keşfetmeye yönelir. Bu da çocuğun daha iyi gelişimini teşvik eder (Howes ve Ritchie, 1998). Ayrıca bağlanma, çocuğun sosyalleşme sürecinin temelini oluşturur (Bergin ve Bergin, 2009). Öğretmenleri ile olumlu ilişkisi olan çocuklar akranlarına, olumlu etkileşim ve olumlu tepkiler beklentisi ile yönelirler (Mitchell-Copeland, Denham, ve DeMulder, 1997) ve akranları ile daha iyi ilişki kurarlar (Coplan, Bullock, Archbell, ve Sandra, 2014). Ancak bütün çocukların öğretmenleri ile bağlanma ilişkisi kurduğunu söylemek güçtür. Öğretmen-çocuk ilişkisi, bağlanma ilişkisinin özelliklerinin bir kısmına sahiptir ve bağlanma ilişkisinin işlevlerinin yalnızca bir kısmını yerine getirir (Bergin ve Bergin, 2009).

\section{EKOLOJIKK SISTEMLER KURAMI}

Öğretmen-çocuk ilişkisini konu edinen çalışmalara kılavuzluk eden bir diğer yaklaşım ise ekolojik sistemler modelidir. Bu model, gelişimin bireylerin kişisel özellikleri, içinde bulundukları bağlamlar ve bu bağlamlarda yer alan 
süreçler arasındaki karşlıklı ilişkilerden beslendiğini öne sürümektedir (Castle vd., 2016). Ekolojik sistemler teorisi olarak da bilinen gelişimsel sistemler teorisi, çocukların farklı etki düzeylerine sahip, yakın ve uzak çevrelerinde yer alan sistemlerden oluşan bir yapı içerisinde geliştiğini savunur. (Sabol ve Pianta, 2012). Çocuğun içinde geliştiği bağlamın en iç katmanı olan Mikro sistemde aile, kardeşler, akranlar, okul, öğretmenler, komşular vb yakın çevredeki kişiler yer alır (Cross ve Hong, 2012; Nasiopoulou, Williams, Sheridan, ve Hansen, 2019). Bu model mikro sistemin bir üyesi olarak öğretmen-çocuk etkileşimlerinin çocukların gelişimini benzersiz bir şekilde etkilediğini öne sürmektedir (Lippard, vd.., 2018). Bronfenbrenner ve Morris (1998) okul öncesi sınıf bağlamında çocuğun gelişimi üzerinde etkisi en büyük olan faktörün öğretmen-çocuk etkileşimi olduğunu belirtmektedir (Hu vd., 2020).

\section{SOSYO-KÜLTÜREL GELİŞIM KURAMI}

Yetişkin ile çocuk etkileşimlerinin, çocuğun gelişimi üzerindeki kritik etkisine vurgu yapan bir diğer kuramcı da Rus psikolog Lev Vygotsky'dir. Ona göre çocuğun gelişimi, yetişkin ile çocuk arasında gerçekleşen benzersiz bir iş birliği ve sosyal etkileşimlerin sonucu olarak gerçekleşir (Veer, 1986). Çocuklar yetişkinler ile yaşadıkları etkileşimler vasıtası ile içinde bulundukları kültürün önemli kabul ettiği bilgi ve becerileri kazanır. Bu aktarımları yapan yetişkinlerden olan öğretmenler, çocuklara toplumsal ve zihinsel birtakım beceriler kazandırarak onların gelişimleri üzerinde etkili olurlar (Öncü, 1999). Çocuklar, ihtiyaçlarına cevap olan yetişkinler ile kurdukları güçlü duygusal bağlar ve etkileşimler sayesinde birtakım beceriler edinirler. Bu ilişkide "çırak" konumunda olan çocuk, içinde geliştiği kültürün fikirlerini içselleştirir (Öncü, 1999; Ünveren Kapanzade, 2019; Veer, 1986). Edindiği bu bilgiler çocuğun gelişimine ve gelecekteki davranışlarına etkide bulunur (Mecacci 2021; Veer 1986).

\section{ÖĞRETMEN ÇOCUK İLİŞİSİNINN ÇOCUĞA ETKİLERİ}

Öğretmen-çocuk etkileşimlerinin kalitesi, okul öncesi çocukların özellikle sosyal-duygusal, bilişsel ve davranışsal özelliklerine hem eş zamanlı hem de uzun vadeli olarak etkide bulunur (Driscoll, Wang, Mashburn, ve Pianta, 2011; Hu vd., 2020; Rojas ve Abenavoli, 2021; Roorda, Koomen, Spilt, ve Oort, 2011; Whitaker, Dearth-Wesley, ve Gooze, 2015). Öyle ki öğretmenlerin niteliklerinin, öğrenci çıktılarındaki varyansın \% 30’una kadar katkıda bulunduğu belirtilmektedir (Hanushek ve Rivkin, 2006; Hattie, 2003).

Öğretmen çocuk ilişkisinin çocuk üzerindeki etkisi bu ilişkinin niteliğine göre farklılaşmaktadır. Öğretmenleri ile olumlu etkileşim içerisinde olan çocukların hem akademik hem de sosyal-duygusal gelişimlerinin daha iyi olduğu bildirilmektedir. Buna göre öğrencileri ile destekleyici ve yakın (sıcak, duyarlı ve açık) ilişkiler kuran öğretmenler çocuklar için öngörülebilir ve güvenli bir sınıf ortamı oluşturarak, çocukların sosyal olarak uyumlu ve bağımsız öğrenen bireyler olmalarına katkı sunar (Varghese, Vernon-Feagans, ve Bratsch-Hines, 2019). Öğretmen ile olumlu etkileşime sahip olmak, çocuğun duygusal/davranışsal problemlerinin daha az, sosyal becerilerinin ise daha gelişkin olmasını teşvik etmektedir (Bulotsky-Shearer vd.., 2020; Colwell ve Lindsey, 2003; Pianta ve Stuhlman, 2004).

Buna karşın öğretmenleri ile olumsuz etkileşim kalıplarına çocukların daha zayıf dil gelişimine (White, 2013; Zhang ve Sun, 2011) ve daha düşük akademik yeterliliğe (Coplan ve Prakash, 2003; Varghese vd., 2019), daha yüksek düzeyde dışa yönelim ve içe yönelim sorunlarına (Bulotsky-Shearer, vd., 2020; Sabol ve Pianta, 2012, Wu, Hu, Fan, Zhang, ve Zhang, 2018) sahip oldukları ve daha fazla sosyal uyum sorunu yaşadıkları belirlenmiştir (Kirkhaug vd, 2016; Pianta, Steinberg, ve Rollins, 1995).

\section{ÖĞRETMEN-ÇOCUK ETKILLEȘiMLERİNIN NITTELİĞİ İLE İLİŞKİİ FAKTÖRLER}

Çocuk üzerinde bu denli önemli bir etki gücüne sahip olan öğretmen-çocuk ilişkisinin niteliğini belirleyen şey nedir? Öğretmen çocuk ilişkisini etkileyen çok sayıda faktör vardır (Sette, Zava, Baumgartner, Laghi, ve Coplan, 2021). Bununla beraber öğretmenler ve çocuklar arasındaki etkileşimlerin kalitesinin üç potansiyel faktörden etkilenebileceği ifade edilmektedir. Bunlar; öğrenme ortamı, çocuk ve öğretmen ile ilgili özellikler olarak sıralanmaktadır (Chung, Marvin, ve Churcill, 2005; Koles vd., 2013).

\section{Ortam İle İlgili Unsurlar}

Öğretmen-çocuk etkileşimine etki eden faktörlerden, öğrenme ortamı ile ilgili olanlar sınıftaki öğrenci sayısı, 
sınıfın materyal ve donanım özellikleri, sınıfın büyüklüğü vb şeklinde sıralanabilir. Yeterli ve uygun materyallere sahip ve daha az sayıda öğrencinin bulunduğu sınıflardaki öğretmen-çocuk etkileşim kalitesinin daha yüksek olduğu belirtilmektedir (Chung vd., 2005). Bununla birlikte sınıf ortamı ile ilgili tüm olumsuzluklara ve çevresel dezavantajlara rağmen öğretmen çocuk ilişkisinin güçlü olduğunu gösteren çalışmaların (Howes, 1997; Mill \& Romano-White, 1999) varlığı, sınıf ortamı ile ilgili faktörlerin öğrenci-çocuk ilişkisinin yalnızca bir kısmını açıkladığına işaret etmektedir (Chung vd., 2005).

Bronfenbrenner ve Moris gibi kuramcılar, çocukla öğretmen arasındaki ilişkinin niteliğinin, büyük oranda çocuğa ve öğretmene ait özelliklerin karşılıklı etkileşimine göre şekillendiğini savunur (Sette vd., 2021). Araştırmalar da öğretmen-çocuk etkileşiminin kalitesinin büyük oranda çocuk ve öğretmenin özellikleri ile yakından ilişkili olduğunu göstermektedir (Pianta ve Howes, 2005).

\section{Çocukla İlgili Özellikler}

Çok sayıda çalışma, çocukla ilgili özelliklerin öğretmen-çocuk ilişkisine etkide bulunabildiğini göstermektedir (Chung vd., 2005; Coplan ve Prakash, 2003; Sette vd., 2021). Çocuğun mizac1, yaşı cinsiyeti, öfke tepkileri, öz kontrol becerileri, çatışma vb özellikleri öğretmen-çocuk ilişkisinin kalitesine etki eden, çocukla ilgili faktörler arasındadır (Koles vd., 2013). Örneğin utangaç çocukların öğretmenleri ile yakın ilişki kurma konusunda güçlük yaşadıkları (Sette vd., 2021), kız çocukların erkek çocuklara kıyasla, öğretmenleri ile daha iyi ilişkiler kurduğu ve iş birliği yaptığı belirtilmektedir (Colwell ve Lindsey, 2003).

\section{Öğretmen İle İlgili Özellikler}

Öğretmenle ilgili çeşitli kişisel özellikler de öğretmen-çocuk etkileşimleriyle ilişkili bir başka faktördür (Castle vd., 2016; Choi ve Dobbs-Oates, 2016). İlișkiler, iki kiși arasındaki karşıllklı etkileşimler aracilığı ile oluşur. Bu nedenle ilişkinin doğası bu iki kișinin özellikleri, davranışları, beklentileri ve algılarından önemli ölçüde etkilenir (Lippard vd., 2018). Ancak öğretmen-çocuk ilișkisinin kalitesinde, öğretmenin bireysel özelliklerinin ve kișiler arası iletișim becerilerinin daha belirleyici olduğu kabul edilir (Sabol ve Pianta, 2012).

Öğretmenlerin eğitim düzeyi (Burchinal, Cryer, Clifford, ve Howes, 2002; Castle vd., 2016; Chung vd., 2005; HaleJinks, Knopf ve Kemple, 2006; Jeon, Buettner, ve Hur, 2016; Wang, vd., 2020; Kabadayl, 2010), mesleki deneyim süreleri (Castle vd., 2016; Choi ve Dobbs-Oates, 2016; Chung vd., 2005; Williford, Wolcott, Whittaker, ve LocasaleCrouch, 2015), çocukların davranışları ve gelişimlerine dair inançları (Castle vd., 2016; Coplan vd., 2014; SusmanStillman, Pleuss, ve Englund, 2013; Williford vd., 2015), mizaç özellikleri (Castle vd., 2016), ruhsal problemleri (Castle vd., 2016; Clarke-Stewart, Vandell , Burchinal, O’Brien ve McCartney, 2002) katıldıkları hizmet içi eğitimler (Jeon vd., 2016; Suchodoletz, Jamil, Larsen, ve Hamre, 2018), aldıkları maaş miktarı (Castle vd., 2016; Jeon vd., 2016) çocuklarla etkileşimleri ile ilişkili faktörler olarak değerlendirilmektedir.

\section{UYUMLU OLMAYAN ARAȘTIRMA SONUÇLARI}

Bununla beraber okul öncesi öğretmenlerin niteliklerinin çocuğun gelişimine nasıl katkıda bulunduğu tam olarak anlaşılamamıştır ve bu konuda yapılan uluslararası çalışmaların sonuçları da tutarlı değildir (Wang vd., 2020). Kimi çalışmalar (Ansari vd., 2020; Burchinal vd., 2002; Castle vd., 2016; Pianta vd., 2005) öğretmenlerin eğitim düzeyinin, çocuklarla etkileşimlerinin kalitesini yordadığını gösterirken diğer bazı çalışmalar (Hu B. Y., Wang, Song, ve Roberts, 2020; Lin ve Magnuson, 2018; Wang, vd., 2020) öğretmenlerin eğitim düzeyinin çocuklarla etkileşimleri ile ilişkisinin olmadığını göstermektedir.

Benzer şekilde öğretmenlerin mesleki deneyim süresi ile çocuklarla etkileşim biçimleri arasındaki ilişkiyi inceleyen araştırmalar da farklı sonuçlar sunmaktadır. Kimi araştırmalar (Ansari, vd., 2020) mesleki deneyim süresi arttıkça öğretmenlerin çocuklarla daha nitelikli ilişkiler kurduğunu gösterirken diğer bazı araştırmalar (Chung vd., 2005; Pianta vd 2005; Wang, vd., 2020) öğretmenin deneyim süresi ile çocuk etkileşimleri arasında anlamlı bir ilişkinin olmadığına işaret etmektedir.

Norveç’te yapılan bir çalışma öğretmenlerin mizaç özelliklerinin sınıftaki pratikleri ile ilişki olduğunu ortaya koymuştur (Djigić, Stojiljković, ve Dosković, 2014). Bir başka çalışmada ise öğretmenlerin mizaçları ve çocuklarla etkileşim biçimleri arasında anlamlı bir ilişki bulunamamıştır (Castle vd., 2016). Bununla beraber öğretmenlerin yüksek depresyon puanlarının, düşük düzeyli öğrenci-çocuk etkileşimi ile ilişkili olduğunu gösteren çok sayıda çalışma 
vardır (Buettner, Jeon, Hur ve Garcia, 2016) 2016; Jeon vd., 2014; Kim ve Kim, 2010; Koles vd., 2013; Kwon, Jeon, Jeon, ve Castle, 2019; Whitaker vd., 2015). Bu veriler, öğretmen-çocuk etkileşimlerinin niteliği ile ilişkili faktörlerin neler olduğu sorusuna henüz net bir cevap verilemediğine işaret etmektedir.

\section{TARTIȘMA}

$\mathrm{Bu}$ makalede, okul öncesi öğretmen-çocuk ilişkisinin çocuk üzerindeki etkileri ve bu ilişkinin kalitesi ile bağlantılı faktörlerin belirlenmesinin öneminden bahsedildi. Yapılan literatür taramasında okul öncesi öğretmençocuk ilişkisinin, çocuğun gelişimi üzerinde önemli düzeyde etkili olduğu ve bu etkinin öğretmen-çocuk etkileşimin niteliğine göre farklılaştığ 1 görülmektedir. Buna göre olumlu etkileşim çocuğun daha iyi bir gelişim göstermesini teşvik ederken, olumsuz etkileşim çocukla ilgili kimi problemlerle ilişkilendirilmektedir. Bununla beraber öğretmen çocuk etkileşiminin niteliğini belirleyen en önemli unsurun öğretmene ait özellikler olduğu görüşünün hâkim olduğu görülmektedir (Sabol ve Pianta, 2012).

Okul öncesi öğretmen-çocuk etkileşiminin çocuk üzerindeki etkisi konusunda önemli ölçüde fikir birliğine varan araştırmacılar, öğretmen-çocuk ilişkisine etkide bulunan öğretmen özellikleri konusunda ise farklı görüşler ortaya koymaktadır. Öğretmenlerin eğitim düzeyi, pedagojik inançları, mesleki deneyim süreleri, ruhsal özellikleri vb değişkenler çok sayıda araştırmaya konu olmuş ancak birbirleri ile uyumlu olmayan sonuçlara ulaşılmıştır. Bu durum farklı metodolojik yaklaşımların kullanılmasının bir sonucu olabilir. Tercih edilen araştırma yöntemi, araştırmada kullanılan ölçme araçları, tercih edilen veri analizi türü ve çalışma grubuna ait kimi farklılıklar araştırmacıların birbirleri ile uyumlu olmayan sonuçlara ulaşmasına neden olabilmektedir (Bernardi ve Boertien, 2017). Örneğin öğretmen-çocuk etkileşimlerinin niteliğini belirlemek için farklı özellikte ölçekler kullanılmakta ve bu ölçekler aynı çalışma gruplarında dahi farklı sonuçlar verebilmektedir. Konu ile ilgili araştırmalarda kullanılan ölçekler öğretmen bildirimine dayalı ölçekler, çocuk bildirimine dayalı ölçekler ve bağımsız gözlemcilerin değerlendirmelerine dayalı ölçekler şeklinde sıralanabilir (Pianta ve Bridget, 2009; White, 2016). Araştırmalar (Hatch ve Freeman, 1988; Wen, Elicker ve McMullen, 2011; Wilcox-Herzog, 2002) öğretmen-çocuk etkileşimine dair, öğretmen bildirimine dayalı ölçeklerle elde edilen veriler ile sınıflarda bağımsız gözlemciler tarafından yapılan gözlemlerle elde edilen verilerin farklı sonuçlar ortaya koyduğunu göstermektedir. Hu, Fan, Yang ve Neitzel, (2017) tarafından yürütülen bir çalışma buna örnektir. Bu çalışmada öğretmenler, çocuklarla ilişkilerinde çocuk merkezli bir yaklaşıma sahip olduklarını bildirmiş ancak aynı sınıflarda sistematik gözlemler yapan bağımsız gözlemciler öğretmenlerin, öğretmen merkezli tutumlar sergilediklerini bildirmiştir.

Ioannidis (2005) ise yukarıdaki faktörlere ek olarak bir alanda yapılan çalışma sayısının az olması durumunda araştırma bulgusunun doğru olma olasılığının azaldığını ve konu ile ilgili daha fazla sayıda araştırma yapılmasının gerçeğe daha yakın sonuçlar elde edilmesine katkı sunacağını belirtmektedir. Ne var ki öğretmen-çocuk etkileşimi ile ilişkili öğretmen özelliklerini belirlemeye yönelik çalışmaların sayısı oldukça sınırlıdır ve bu konuda farklı kültürel gruplarda daha fazla sayıda çalışma yapılması gerekmektedir (Jingbo ve Elicker, 2005).

Öte yandan konu ile ilgili daha önce yapılmış çalışmalar, öğretmenlerin sınıf süreçlerindeki tepkilerinin, öğretmene ait üç temel özelliğe göre şekillendiğini ifade etmektedirler; öğretmenin eğitim düzeyi, mesleki deneyim süreci ve pedagojik inançları (Ansari \& Pianta, 2019). Ancak öğretmenlerin eğitim düzeyi ile çocuklarla etkileşimlerinin kalitesi arasındaki ilişki yeterince açık değildir. Başka bir ifade ile daha yüksek eğitim düzeyine sahip olmak her zaman daha yüksek bir etkileşim kalitesi ile sonuçlanmıyor (Lin ve Magnuson, 2018; Wang, Song, ve Roberts, 2020). Öğretmenin eğitim düzeyinin, çocuklarla etkileşim kalite göstergelerinin yalnızca bir kısmı ile ilişkili olduğu kabul edilmektedir (Pianta \& Howes, 2005). Benzer şekilde mesleki deneyim süresinin daha fazla olması da her zaman öğretmenin çocuklarla daha iyi ilişkiler kurmasını sağlamamaktadır (Pianta vd 2005; Wang, vd., 2020). Buna bağlı olarak öğretmenin eğitim düzeyi ve mesleki deneyim süresinin çocuklarla etkileşim kalitesi arasındaki ilişki de aracı değişkenlerin varlığından söz edilebilir. Bu nokta da üçüncü değişken olarak öğretmenin pedagojik bilgi ve inançlarının, çocuklarla etkileşim sürecindeki rolü dikkat çekmektedir. Öğretmenlerin, çocukların davranışlarına dair inançları, öğretmen-çocuk etkileşimlerinin kalitesi ile güçlü şekilde ilişkili olabilir. Sakellariou ve Rentzou (2012), okul öncesi öğretmenlerin inançlarının, sınıf uygulamaları ile ilgili kararlar üzerinde büyük etkileri olduğunu belirtmektedir. Ansari ve Pianta (2019) da öğretmen-çocuk etkileşimlerinin kalitesinin hangi faktörlerle ilişkili olduğunu inceleyen araştırmaların, tutarlı olmayan sonuçlar sunduğunu bununla beraber sınıf ortamında daha iyi pratikler sergileyen öğretmenlerin özel bazı bilgi ve stratejilere sahip olduğunu belirterek öğretmenlerin pedagojik bilgi ve inançlarının önemine işaret etmektedirler. Buna göre "gelişimsel olarak uygun inançları" olan öğretmenler, 
sınıf süreçlerinde çocukların davranışlarını daha doğru yorumlamakta, çocukların gelişimsel ihtiyaçlarını daha iyi tespit etmekte ve çocuklara karşı daha olumlu tutumlar sergilemektedir. Öğretmenlerin, çocuk gelişiminin doğasını daha iyi tanımalarını ve çocuk davranışlarını daha iyi yorumlamalarını sağlayacak içerik ve uygulamalardan oluşan hizmet içi eğitim programlarına katıldıktan sonra çocuklarla daha olumlu ilişkiler kurduğunu gösteren çalışmalar da bu görüşü desteklemektedir (Sutherland, ve diğerleri, 2018; Williford, ve diğerleri, 2017).

Peki öğretmenlerin pedagojik bilgi ve inançları nasıl şekillenmektedir? Bazı öğretmenler çocuk merkezli inançlara sahip iken diğerlerinin yetişkin merkezli inançlara sahip olmasının arkasında hangi dinamikler rol oynamaktadır? Bu sorulara verilen cevaplar arasında iki unsurun özellikle öne çıktı̆̆ 1 görülmektedir; eğitim geçmişi ve mesleki deneyim süresi (Wieduwilt, Lehrl ve Anders, 2021). Ancak öğretmenin aldığı eğitim ve mesleki deneyim süresine bağlı olarak gelişen pedagojik bilgi ve inançları bir yönü ile öğretmenin kişisel özellikleri ile görünmektedir (Early, ve diğerleri, 2007). Bir başka ifade ile aynı eğitimleri almış ve aynı mesleki deneyim süresine sahip öğretmenlerin çocuklarla etkileşim biçimleri, öğretmenlerin kişisel özelliklerine göre farklılaşabilmektedir. $\mathrm{Bu}$ durumda öğretmenin hangi kişisel özelliklerinin bu ilişkide rol aldığını belirlemek önemli bir ihtiyaç olarak belirmektedir. Early ve arkadaşları da (2007) öğretmen-çocuk etkileşiminin kalitesi ile öğretmenin aldığı eğitim ve sahip olduğu mesleki deneyim süresi arasındaki ilişki incelenirken öğretmenin kişisel özelliklerinin iyi irdelenmesi gerektiğini belirtmektedir.

Özetle okul öncesi öğretmen-çocuk etkileşimlerinin kalitesi öğretmenin pedagojik bilgi ve inançları ile güçlü şekilde ilişkili görünmektedir. Özellikle çocuk merkezli inançlara sahip okul öncesi öğretmenlerin çocuklarla daha iyi etkileşim kurdukları bildirilmektedir. Bununla beraber öğretmenlerin pedagojik bilgi ve inançlarının nasıl ve hangi faktörlere şekillendiğini belirlemeye yönelik daha fazla sayıda çalışmaya ihtiyaç duyulmaktadır. Bu amaçla öğretmenlerin eğitim düzeyi ve deneyim sürelerine ek olarak mizaç, ruh sağlığı, cinsiyet, yaş vb kişisel özellikleri ile sahip oldukları pedagojik bilgi ve inançlar arasındaki ilişkinin incelenmesi konu ile ilgili literatüre katkı sunabilir.

Ayrıca öğretmen çocuk etkileşimlerinin kalitesi ile ilişkili faktörleri belirlemek, küçük çocukların okul öncesi süreçlerinin daha verimli olmasını sağlayabilir. Daha iyi ilişkilerin küçük çocukların hem akademik hem de sosyalduygusal yeterlilikleri üzerindeki olumlu etkisi buna işaret etmektedir.

Yapılan literatür taramasında Türkiye'de de okul öncesi öğretmen-çocuk etkileşimleri ile ilişkili öğretmen özelliklerini konu edinen çalışmaların sınırlı sayıda olduğu görülmüştür. Oysa tüm dünyada olduğu gibi Türkiye’de de okul öncesi okullaşma oranı büyük bir hızla artmaktadır. Milli Eğitim Bakanlığının verilerine göre göre 2019-2020 eğitim-öğretim yılında okul öncesi eğitime devam eden öğrenci sayısı 1.629.740 olarak belirlenmiştir (MEB, 2020). $\mathrm{Bu}$ durum gelişimsel bir bağlam olarak okul öncesi sınıflardaki çocuk yetişkin etkileşimlerinin kapsamlı şekilde incelenmesini gerektirmektedir.

\section{KAYNAKÇA}

Ahmad, A., \& Sahak, R. (2009). Teahcer-Student Attachment And Teachers' Attitudes Towards Work. Jurnal Pendidik dan Pendidikan, 24, 55-72.

Ansari, A., \& Pianta, R. C. (2019). Teacher-child interaction quality as a function of classroom age diversity and teachers' beliefs and qualifications. APPLIED DEVELOPMENTAL SCIENCE, 23(3), 294-304. doi:10.1080/10888.691.2018.1439749

Ansari, A., Pianta, R. C., Whittaker, J. V., Vitiello, V. E., \& Ruzek, E. A. (2020). Preschool Teachers' Emotional Exhaustion in Relation to Classroom Instruction and Teacher-child Interactions. Early Education and Development, 1-15. doi:10.1080/1 0409.289.2020.1848301

Ası, D. Ş., \& Karabay, Ş. O. (2018). Öğrenci - Öğretmen İlişki Ölçeği-Kısa Formunun Türkçe’ye Uyarlanması. Ege Eğitim Dergisi / Ege Journal of Education, 19(1), 67-82. doi:10.12984/egeefd.322358

Baker, J. A., Grant, S., \& Morlock, L. (2008). The Teacher-Student Relationship As a Developmental Context for Children With Internalizing or Externalizing Behavior Problems. School Psychology Quarterly, 23(1), 3-15. doi:10.1037/1045-3830.23.1.3

Bergin, C., \& Bergin, D. (2009). Attachment in the Classroom. Educational Psychology Review, 21, 141-170. doi:10.1007/ s10648.009.9104-0

Bernardi, F., \& Boertien, D. (2017). Explaining Conflicting Results in Research on the Heterogeneous Effects of Parental Separation on Children's Educational Attainment According to Social Background. Eur J Population, 33, 243-266. doi:10.1007/ s10680.017.9417-5 
Buettner, C. K., Jeon, L., Hur, E., \& Garcia, R. E. (2016). Teachers' Social-Emotional Capacity: Factors Associated With Teachers' Responsiveness and Professional Commitment. Early Education and Development, 27(7), 1018-1039. doi:10.1080/10409.2 89.2016.1168227

Bulotsky-Shearer, R. J., Fernandez, V. A., Bichay-Awadalla, K., Bailey, J., Futterer, J., \& Qi, C. H. (2020). Teacher-child interaction quality moderates social risks associated with problem behavior in preschool classroom contexts. Journal of Applied Developmental Psychology, 67, 1-12. doi:10.1016/j.appdev.2019.101103

Burchinal, M. R., Debby , C., Clifford, R. M., \& Howes, C. (2002). Caregiver Training and Classroom Quality in Child Care Centers. Applied Developmental, 6(1), 2-11. doi: 10.1207/S1532480XADS0601_01

Burchinal, M. R., Peisner-Feinberg, E., Pianta, R., \& Howes, C. (2002). Development of Academic Skills from Preschool Through Second Grade: Family and Classroom Predictors of Developmental Trajectories. Journal of School Psychology, 40(5). doi:10.1016/S0022-4405(02)00107-3

Castle, S., Williamson, A. C., Young, E., Stubblefield, J., Laurin, D., \& Pearce, N. (2016). Teacher-Child Interactions in Early Head Start Classrooms: Associations With Teacher Characteristics. Early Education and Development, 27(2), 259-274. doi:10.10 80/10409.289.2016.1102017

Choi, J. Y., \& Dobbs-Oates, J. (2016). Teacher-Child Relationships: Contribution of Teacher and Child Characteristics. Journal of Research in Childhood Education, 30(1), 15-28. doi:10.1080/02568.543.2015.1105331

Chung, L.-C., Marvin, C., \& Churcill, S. L. (2005). Teacher factors associated with preschool teacher-child relationships: teaching efficacy and parent-teacher relationships. Journal of Early Childhood Teacher Education, $131-142$. doi:10.1080/109.010.2050250206

Clarke-Stewart, K., Vandell, D. L., Burchina, M., O’Brien , M., \& McCartney, K. (2002). Do regulable features of child-care homes affect children's development? Early Childhood Research Quarterly, 17, 52-86. doi:10.1016/S0885-2006(02)00133-3

Colwell, M. J., \& Lindsey, E. W. (2003). acher-Child Interactions and Preschool Children's Perceptions of Self and Peers. Early Child Development and Care,, 173(2-3), 249-258. doi:10.1080/030.044.3031000071888

Commodari, E. (2013). Preschool teacher attachment, school readiness and risk of learning difficulties. Early Childhood Research Quarterly, 28, 123-133. doi:10.1016/j.ecresq.2012.03.004

Coplan, R. J., \& Prakash, K. (2003). Spending time with teacher: characteristics of preschoolers who frequently elicit versus initiate interactions with teachers. Early Childhood Research Quarterly, 18, 143-158. doi:10.1016/S0885-2006(03)00009-7

Coplan, R. J., Bullock, A., Archbell, K. A., \& Sandra, B. (2014). QuarterlyPreschool teachers' attitudes, beliefs, and emotional reactions toyoung children's peer group behaviors. Early Childhood Research Quarterly, 11-22. doi:10.1016/j.ecresq.2014.09.005

Cross , D. I., \& Hong, J. Y. (2012). An ecological examination of teachers' emotions in the school context. Teaching and Teacher Education, 28, 957-967. doi:10.1016/j.tate.2012.05.001

De Schipper, E. J., Riksen-Walraven, J., \& Geurts, S. (2006). Effects of Child-Caregiver Ratio on the Interactions Between Caregivers and Children in Child-Care Centers: An Experimental Study. Child Development, 77(4), 861-874.

Djigić, G., Stojiliković, S., \& Dosković, M. (2014). Basic personality dimensions and teachers' self-efficacy. Procedia - Social and Behavioral Sciences, 112, 593-602. doi:10.1016/j.sbspro.2014.01.1206

Dozier, M., Stovall, K. C., Albus, K. E., \& Bates, B. (2001). Attachment for Infants in Foster Care: The Role of Caregiver State of Mind. Child Development, 5, 1467-1477.

Driscoll, K. C., \& Pianta, R. C. (2010). Banking Time in Head Start: Early Efficacy of an Intervention Designed to Promote Supportive Teacher-Child Relationships. Early Education and Development, 21(1), 38-64. doi:10.1080/104.092.80802657449

Driscoll, K. C., Wang, L., Mashburn, A. J., \& Pianta, R. C. (2011). Fostering Supportive Teacher-Child Relationships:Intervention Implementation in a State-Funded Preschool Program. Early Education \& Development, 22(4), 593-619. doi:10.1080/1040 9.289.2010.502015

Early, , D. M., Maxwell, K. L., Burchinal, M., Bender, R. H., Ebanks, C., Henry, G. T., . . Zill, N. (2007). Teachers' Education, Classroom Quality, and Young Children's Academic Skills: Results From Seven Studies of Preschool Programs. Child Development, 78(2), 558-580.

Fani, T., \& Ghaemi, F. (2011). Implications of Vygotsky's Zone of Proximal Development (ZPD) in Teacher Education: ZPTD and Self-scaffolding. Procedia - Social and Behavioral Sciences, 29, 1549-1554. doi:10.1016/j.sbspro.2011.11.396

Hale-Jinks, C., Knopf, H., \& Knopf, H. (2006). Tackling Teacher Turnover in Child Care: Understanding Causes and Consequences, Identifying Solutions. Childhood Education, 82(4), 219-226. doi:10.1080/00094.056.2006.10522826 
Hanushek, E. A. (2006). Teacher Quality. E. Hanushek, \& S. Rivkin içinde, Handbook of the Economics of Education (Cilt 1, s. 1051-1078). Elsevier.

Hatch, J. A., \& Freeman, E. B. (1988). Kindergarten philosophies and practices: Perspectives of teachers, principals, and supervisors. Early Childhood Research Quarterly, 3(2), 151-166. doi:10.1016/0885-2006(88)90019-1

Hattie, J. (2003). Teachers make a difference: What is the research evidence? ACER Research Conference. Melbourne: Australian Council for Educational Research.

Howes, C. (1997). Children's Experiences in Center-Based Child Care as a Function of Teacher Background and Adult : Child Ratio. Merrill-Palmer Quarterly, 43(3), 404-425.

Howes, C., \& Ritchie, S. (1998). Changes in Child-Teacher Relationships in a Therapeutic Preschool Program. Early Education \& Development, 9(4), 411-422. doi:10.1207/s15566935eed0904_6

Hu, B. Y., Fan, X., Yang, Y., \& Neitzel , J. (2017). Chinese preschool teachers' knowledge and practice of teacher-child interactions: The mediating role of teachers' beliefs about children. Teaching and Teacher Education, 63, 137-147. doi:10.1016/j. tate.2016.12.014

Hu, B. Y., Wang, S., Song, Y., \& Roberts, S. K. (2020). Profiles of Provision for Learning in Preschool Classrooms in Rural China: Associated Quality of Teacher-child Interactions and Teacher Characteristics. Early Education and Development. doi: 10.1080/10409.289.2020.1802567

Hu, B., Wang, S., Song, Y., \& LoCasale-Crouch, J. (2020). Exploring the complex relationship between developmentally appropriate activities and teacher-child interaction quality in rural Chinese preschools. Children and Youth Services Review, 116, 1-10. doi:10.1016/j.childyouth.2020.105112

Hutchings, J., Martin-Forbes, P., Daley, D., \& Williams, M. E. (2013). A randomized controlled trial of the impact of a teacher classroom management program on the classroom behavior of children with and without behavior problems. Journal of School Psychology, 51, 571-585. doi:10.1016/j.jsp.2013.08.001

Ioannidis, J. (2005). Why Most Published Research Findings Are False. PLOS Medicine, 2(8). doi:10.1371/journal.pmed.0020124

Ivanova, R., Berechikidze, I., Gazizova, F., Gorozhanina, E., \& Ismailova, N. (2020). Parent-teacher interaction and its role in preschool children's development in Russia. Education 3-13, 48(6), 704-715. doi:10.1080/03004.279.2019.1646296

Jeon, L., Buettner, C. K., \& Hur, E. (2016). Preschool Teachers' Professional Background, Process Quality, and Job Attitudes: A Person Centered Approach. Early Education and Development, 27(4), 551-571. doi:10.1080/10409.289.2016.1099354

Jingbo, L., \& Elicker, J. (2005). Teacher-child interaction in Chinese kindergartens: an observational analysis. International Journal of Early Years Education, 13(2), 129-143. doi: 10.1080/096.697.60500171139

Kabaday1, A. (2010). Investigating demographic characteristics and teaching perceptions of Turkish preschool teachers. Early Child Development and Care, 180(6), 809-822. doi:10.1080/030.044.30802445501

Kara, H. E., Gönen, M. S., \& Pianta, R. (2017). Öğretmen Çocuk Etkileşiminin Niteliği ile Çocukların Öz Düzenleme Becerisi Arasındaki İlişkinin İncelenmesi. Hacettepe Üniversitesi Eğitim Fakültesi Dergisi, 32(4), 880-895. doi:10.16986/ HUJE.201.601.8694

Keefe-Cooperman, K., \& Brady-Amoon, P. (2014). Preschooler Sleep Patterns Related to Cognitive. Early Education and Development, 25, 859-874. doi:10.1080/10409.289.2014.876701

Kesebir, S., Özdoğan-Kavzoğlu, S., \& Üstündağ, M. F. (2011). Bağlanma ve Psikopatoloji. Psikiyatride Güncel Yaklaşımlar, 3(2), 321-342.

Kim, Y. H., \& Kim, Y. E. (2010). Korean early childhood educators' multi-dimensional teacher self-efficacy and ECE center climate and depression severity in teachers as contributing factors. Teaching and Teacher Education, 26, 1117-1123. doi:10.1016/j. tate.2009.06.009

Kirkhaug, B., Drugli, M. B., Handegård, B. H., Lydersen, S., Åsheim, M., \& Fossum, S. (2016). Does the Incredible Years Teacher Classroom Management Training programme have positive effects for young children exhibiting severe externalizing problems in school?: a quasi-experimental pre-post study. BMC Psychiatry, 16, 1-11. doi:10.1186/s12888.016.1077-1

Koles, B., O'Connor, E., \& Collins, B. A. (2013). Associations between child and teacher characteristics and quality of teacher-child relationships: the case of Hungary. European Early Childhood Education Research Journal, 21(1), 53-76. doi:10.1080/1350293X.2012.760337

Kwon, K.-A., Castle, S., Jeon, S., \& Jeon, L. (2019). The role of teachers' depressive symptoms in classroom quality and child developmental outcomes in Early Head Start programs. 74. doi:10.1016/j.lindif.2019.06.002. 
Lin, Y.-C., \& Magnuson, K. A. (2018). Classroom quality and children's academic skills in child care centers: Understanding the role of teacher qualifications. Early Childhood Research Quarterly, 42, 215-227. doi:10.1016/j.ecresq.2017.10.003

Lippard, C., La Paro, K., Rouse, H., \& Crosby, D. (2018). A Closer Look at Teacher-Child Relationships and Classroom Emotional Context in Preschool. Child Youth Care Forum, 47, 1-21. doi:10.1007/s10566.017.9414-1

Liu, T., Zhang, X., Zhao, K., \& Chan, W.L.(2020). Teacher-child relationship quality and Chinese toddlers' developmental functioning: A cross-lagged modelling approach. Children and Youth Services Review, 116. doi:10.1016/j.childyouth.2020.105192.

Lynch, M., \& Cicchetti, D. (1997). Children's Relationships with Adults and Peers:An Examination of Elementary and Junior High School Students. Journal of School Psychology, 35(1), 81-99.

MEB. (2020). MİLLî EĞİTİM İSTATİSTİKLERİ / ÖRGÜN EĞİTİM 2019-2020. Ankara: Milli Eğitim Bakalığı.

Mecacci, L. (2021). Vygotsky and Psychology as Normative Science. Integrative Psychological and Behavioral Science. doi:10.1007/ s12124.021.09638-4

Mill, D., \& Romano-White, D. (1999). Correlates of affectionate and angry behavior in child care educators of preschool-aged children. Early Childhood Research Quarterly, 14(2), 155-178. doi:10.1016/S0885-2006(99)00007-1

Mitchell-Copeland, J., Denham, S. A., \& DeMulder, E. K. (1997). Q-Sort Assessment of Child-Teacher Attachment Relationships and Social Competence in the Preschool. Early Education and Development, 8(1), 27-39. doi:10.1207/s15566935eed0801_3

Nasiopoulou, P., Williams, P., Sheridan, S., \& Hansen, K. Y. (2019). Exploring preschool teachers' professional profiles in Swedish preschool: a latent class analysis. Early Child Development and Care, 189(8), 1306-1324. doi:10.1080/03004.430.2017.137 5482

Öncü, T. (1999). Lev S. Vygotsky’nin Gelişim Kuramı. Ankara Üniversitesi Dil-Tarih ve Coğrafya Fakültesi Dergisi, 39(1-2), 227236.

Paulus, F. W., Ohmann, S., \& Popow, C. (2016). Practitioner Review: School-based interventions in child mental health. Journal of Child Psychology and Psychiatry, 57(12), 1337-1359. doi:10.1111/jcpp.12584

Pianta, R. C. (1997). Adult-Child Relationship Processes and Early Schooling. Early Education and Development, 8(1), 11-26. doi:10.1207/s15566935eed0801_2

Pianta, R. C., \& Bridget, H. K. (2009). Conceptualization, Measurement, and Improvement of Classroom Processes: Standardized Observation Can Leverage Capacity. Educational Researcher, 38(2), 109-119. doi:10.3102/0013189X09332374

Pianta, R. C., \& Stuhlman, M. W. (2004). Teacher-Child Relationships and Children's Success in the First Years of School. School Psychology Review, 33(3), 444-458. doi: 10.1080/02796.015.2004.12086261

Pianta, R. C., Steinberg, M., \& Rollins, K. (1995). The first two years of school: Teacher-child relationships and deflections in children's classroom adjustment. Development and Psychopathology, 7(2), 295-312. doi:10.1017/S095.457.9400006519

Pianta, R., \& Howes, C. (2005). Features of Pre-Kindergarten Programs, Classrooms, and Teachers: Do They Predict Observed Classroom Quality and Child-Teacher Interactions? Applied Developmental Science, 9(3), 144-159. doi:10.1207/ s1532480xads0903_2

Pianta, R., Howes, C., Burchinal, M., Bryant, D., Clifford, R., Early, D., \& Barbarin, O. (2005). Features of Pre-Kindergarten Programs, Classrooms, and Teachers: Do They Predict Observed Classroom Quality and Child-Teacher Interactions? Applied Developmental Science, 9(3), 144-159. doi:10.1207/s1532480xads0903_2

Qutaiba, A. (2010). The relationship between the level of school-involvement and "Learned helplessness "among special-education Arab-Palestinian teachers in Israel. Procedia Social and Behavioral Sciences, 5, 1326-1333. doi:10.1016/j.sbspro.2010.07.283

Rojas , N. M., \& Abenavoli, R. M. (2021). Preschool teacher-child relationships and children's expressive vocabulary skills: The potential mediating role of profiles of children's engagement in the classroom. Early Childhood Research Quarterly, 56, 225235. doi:10.1016/j.ecresq.2021.04.005

Roorda, D. L., Koomen, H. M., Spilt, J. L., \& Oort, F. J. (2011). The Influence of Affective Teacher-Student Relationships on Students' School Engagement and Achievement: A Meta-Analytic Approach. Review of Educational Research, 81(4), 493529. doi:10.3102/003.465.4311421793

Sabol, T. J., \& Pianta, R. C. (2012). Recent trends in research on teacher-child relationships. Attachment \& Human Development, 14(3), 213-231. doi:10.1080/14616.734.2012.672262

Sakellariou, M., \& Rentzou, K. (2012). Cypriot Pre-Service Kindergarten Teachers' Beliefs and Intensions about the Importance of Teacher/Child Interactions. Early Childhood Educ J, 39, 413-420. doi:10.1007/s10643.011.0472-y

Schipper, E. J., Riksen-Walraven, J., \& Geurts, S. (2006). Effects of Child -Caregiver Ratio on the Interactions Between Caregivers 
and Children in Child-Care Centers: An Experimental Study. Child Development, 77(4), 861-874.

Schuengel, C. (2012). Teacher-child relationships as a developmental issue. Attachment \& Human Development, 14(3), 329-336. doi:10.1080/14616.734.2012.675639

Sette, S., Zava, F., Baumgartner, E., Laghi, F., \& Coplan, R. (2021). Exploring the Role of Play Behaviors in the Links between Preschoolers' Shyness and Teacher-Child Relationships. Early Education and Development. doi:10.1080/10409.289.2021.1 885237

Suchodoletz, A. v., Fäsche, A., Gunzenhauser, C., \& Hamre, B. (2014). A typical morning in preschool: Observations of teacher-child child interactions in German preschools. Early Childhood Research Quarterly, 29, 509-519. doi:10.1016/j. ecresq.2014.05.010

Suchodoletz, A. v., Jamil , F. M., Larsen, R. A., \& Hamre, B. K. (2018). Personal and contextual factors associated with growth in preschool teachers' self-efficacy beliefs during a longitudinal professional development study. Teaching and Teacher Education, 75, 278-289. doi:10.1016/j.tate.2018.07.009

Susman-Stillman, A., Pleuss, J., \& Englund, M. M. (2013). Attitudes and beliefs of family - and center-based child care providers predict differences in caregiving behavior over time. Early Childhood Research Quarterly, 28, 905-917. doi:10.1016/j. ecresq.2013.04.003

Sutherland, K. S., Conroy, M. A., Algina, J., Ladwig, C., Jessee, G., \& Gyure, M. (2018). Reducing child problem behaviors and improving teacher-child interactions and relationships: A randomized controlled trial of BEST in CLASS. Early Childhood Research Quarterly, 42, 31-43. doi:10.1016/j.ecresq.2017.08.001

Thomason, A. C., \& La Paro, K. (2009). Measuring the Quality of Teacher-Child Interactions in Toddler Child Care. Early Education and Development, 20(2), 285-304. doi:10.1080/104.092.80902773351

Tüzün, O., \& Sayar, K. (2006). Bağlanma Kuramı ve Psikopatoloji. Düşünen Adam, 19(1), 24-39.

Ünveren Kapanazde, D. (2019). Vygostky’nin Sosyo - Kültürel ve Bilişsel Gelişim Teorisi Bağlamında Türkçe Öğretiminin Değerlendirilmesi. SDÜ Fen-Edebiyat Fakültesi Sosyal Bilimler Dergisi,(47), 181-195.

Varghese, C., Vernon-Feagans,, L., \& Bratsch-Hines , M. (2019). Associations between teacher-child relationships, children's literacyachievement, and social competencies for struggling andnon-struggling readers in early elementary school. Early Childhood Research Quarterly, 47, 124-133. doi:10.1016/j.ecresq.2018.09.005

Veer, V. D. (1986). Vygotsky’s Developmental Psychology. Psychological Reports, 59, 527-536.

Verschueren, K., \& Koomen, H. M. (2012). Teacher-child relationships from an attachment perspective. Attachment \& Human Development, 14(3), 205-2011. doi:10.1080/14616.734.2012.672260

Wang, L., Dang, R., Bai, Y., Zhang, S., Liu, B., Zheng, L., . . Song, C. (2020). Teacher qualifications and development outcomes of preschoolchildren in rural China. Early Childhood Research Quarterly, 53, 355-369. doi:doi.org/10.1016/j.ecresq.2020.05.015

Wen, X., Elicker, J. G., \& McMullen, M. B. (2011). Early Childhood Teachers' Curriculum Beliefs: Are They Consistent With Observed Classroom Practices? Early, 22(6), 945-969. doi:10.1080/10409.289.2010.507495

Whitaker, R. C., Dearth-Wesley, T., \& Gooze, R. A. (2015). Workplace stress and the quality of teacher-children relationships in Head Start. Early Childhood Research Quarterly, 30, 57-69. doi:10.1016/j.ecresq.2014.08.008

White, K. M. (2013). Associations between teacher-child relationships and children's writing in kindergarten and first grade. Early Childhood Research Quarterly, 28(1), 166-176. doi:10.1016/j.ecresq.2012.05.004

White, K. M. (2016). "My Teacher Helps Me": Assessing Teacher-Child Relationships From the Child's Perspective. Journal of Research in Childhood Education, 30(1), 29-41. doi:10.1080/02568.543.2015.1105333

Wieduwilt, N., Lehrl, S., \& Anders, Y. (2021). Preschool teachers' pedagogical beliefs in the field of language. Teaching and Teacher Education, 101, 1-11. doi:10.1016/j.tate.2021.103296

Wilcox-Herzog, A. (2002). Is There a Link Between Teachers' Beliefs and Behaviors? Early Education and Development, 13(1), , 81-106. doi:10.1207/s15566935eed1301_5

Williford, A. P., LoCasale-Crouch, J., Whittaker, J. V., DeCoster, J., Hartz, K. A., Carter, L. M., ... Hatfield, B. E. (2017). Changing Teacher-Child Dyadic Interactions to Improve Preschool Children's Externalizing Behaviors. Child Development, 88(5), 1544-1553. doi: 10.1111/cdev.12703

Williford, A. P., Wolcott , C. S., Whittaker, J. V., \& Locasale-Crouch, J. (2015). Program and Teacher Characteristics Predicting the Implementation of Banking Time with Preschoolers Who Display Disruptive Behaviors. Prevention Science •, 16, 10541063. doi:10.1007/s11121.015.0544-0 . 
Wu, Z., Hu, B. Y., Fan, X., Zhang, X., \& Zhang, J. (2018). The associations between social skills and teacher-child relationships: A longitudinal study among Chinese preschool children. Children and Youth Services Review, 88, 582-590. doi:doi. org/10.1016/j.childyouth.2018.03.052

Yang, Y., \& Hu, B. Y. (2019). Chinese preschool teachers' classroom instructional support quality and child-centered beliefs: A latent profile analysis. Teaching and Teacher Education, 80, 1-12. doi:10.1016/j.tate.2018.12.021

Zano, G. (2018). Attitudes of caregivers in the infant class in the day-care centre. Early Child Development and Care, 190(9), 1396-1410 . doi:doi.org/10.1080/03004.430.2018.1538134

Zhang, X., \& Sun, J. (2011). The Reciprocal Relations Between Perceptions of Children's Behavior Problems and Teacher-Child Relationships in the First Preschool Year. The Journal of Genetic Psychology, 172(2), 176-198. doi:10.1080/00221.325.201. 528077 


\title{
Factors Affecting the Quality of Preschool Teacher-Child Interactions
}

\author{
Savaș EVCIN (iD), Rengin ZEMBAT iD
}

Child-adult interactions in the preschool period are a central element of the child's development (Pianta., 1997; Sabol \& Pianta, 2012). The family model with two employed parents has become increasingly common in both Western and Asian societies, which has resulted in an increased frequency of out-of-home care for young children (Liu, Zhang, Zhao, \& Chan, 2020; Zano, 2018). Preschool teacher-child interactions in these environments have a strong and permanent impact on the child's basic characteristics (Thomason \& La Paro, 2009). Attachment theory, ecological systems theory, and socio-cultural development theory also argue that teachers have a critical impact on children's psychological structuring (Bergin \& Bergin, 2009; Fani \& Ghaemi, 2011; Qutaiba, 2010; Sabol \& Pianta, 2012; Schuengel, 2012; Verschueren \& Koomen, 2012).

The quality of teacher-child interactions has both simultaneous and long-term effects on preschool children's social-emotional, cognitive, and behavioral characteristics (Hu B., Wang, Song, \& Lo Casale-Crouch, 2020). Having a positive interaction with the teacher encourages the child to have fewer emotional/behavioral problems, more developed social skills, and higher academic success (Bulotsky-Shearer, et al., 2020; Pianta \& Stuhlman, 2004).

It is believed that the quality of the preschool teacher-child relationship is largely determined by the individual characteristics of the teacher and the interpersonal communication skills (Sabol \& Pianta, 2012). Teachers' educational level (Hale-Jinks, Knopf \& Kemple, 2006; Jeon, Buettner, \& Hur. , 2016; Wang, et al., 2020), duration of professional experience (Castle et al., 2016; Choi \& Dobbs-Oates, 2016), beliefs about children's behaviors and development (Coplan vd., 2014; (Williford, Wolcott, Whittaker, \& Locasale-Crouch, 2015)), and mental problems (Clarke-Stewart, Vandell, Burchinal, O'Brien, and McCartney, 2002) are considered to be factors associated with their interactions with children. However, the results of international studies on this subject are not consistent with each other (Wang, et al., 2020).

\section{Conclusion and Suggestions}

The literature review shows that the preschool teacher-child relationship has a significant impact on the development of the child, which varies depending on the quality of the teacher-child interaction. Researchers have different views on teacher characteristics that affect the teacher-child relationship. This can be explained by the use of different methodological approaches. The preferred research methodology, measurement tools, data analysis type, and some differences in the study group may lead researchers to achieve inconsistent results (Bernardi \& Boertien, 2017).

Ioannidis (2005), on the other hand, states that the small number of studies conducted in a field causes a decreased probability of correct results and that further studies on the subject will contribute to achieving results closer to reality. It seems that there is a limited number of studies on teacher characteristics associated with preschool teacher-child interactions in Turkey.

Previous studies show that there are strong links between preschool teachers' pedagogical knowledge and beliefs and their interactions with children (Ansari \& Pianta, 2019; Sakellariou \& Rentzou, 2012). However, it is not clear enough how teachers' pedagogical beliefs are shaped. Further studies are required to determine which personal 
characteristics are related to the pedagogical beliefs of teachers, apart from the education they received before and the period of time in which they have gained professional experience.

Conducting more quantitative studies to determine teacher characteristics associated with the quality of preschool teacher-child interactions, developing new measurement tools, and studying with different groups may contribute to determining which personal characteristics of teachers are associated with these interactions. Results from these studies may enable children to experience better quality teacher interactions in preschool classrooms. 